\title{
SÍNTESE E CARACTERIZAÇÃo DE PARTÍCULAS A BASE DE TITÂNIA E ZINCO DOPADAS COM FERRO
}

\author{
A.L.S. COELHO ${ }^{1}$, A. F. ALMEIDA NETO ${ }^{2}$, L.M.M. JORGE ${ }^{1}$, O. A. A. SANTOS ${ }^{1 *}$ \\ ${ }^{1}$ Universidade Estadual de Maringá, Departamento de Engenharia Química \\ ${ }^{2}$ Universidade Estadual de Campinas, Faculdade de Engenharia Química \\ e-mail: oneliaandreo@hotmail.com
}

\begin{abstract}
RESUMO
Neste trabalho foram desenvolvidos materiais a base de $\mathrm{TiO}_{2}$ e $\mathrm{ZnO}$, importantes semicondutores, dopados com diferentes cargas metálicas de ferro $(5,8,10$ e 15\%, em massa) visando aumentar as suas atividades fotoredutoras, podendo ser usados posteriormente na redução de poluentes orgânicos e inorgânicos. Os materiais obtidos foram calcinados a $400^{\circ} \mathrm{C}$ por 4 horas e caracterizados por medidas de adsorçãodessorção de nitrogênio (determinação da área superficial específica, raio médio e volume específico de poros), análises térmicas (análise termogravimétrica e calorimetria exploratória diferencial), difratometria de raios X, microscopia eletrônica de varredura, espectroscopia de energia dispersiva, espectroscopia fotoacústica e ponto de carga zero. A presença de ferro na estrutura da titânia e do óxido de zinco, aliada ao efeito do tratamento térmico de calcinação modificou de forma considerável a área superficial específica, o raio médio e o volume de poros, bem como a cristalinidade, o band gap, a composição e a distribuição de cargas na superfície dos materiais semicondutores dopados com ferro.
\end{abstract}

\section{INTRODUÇÃO}

Materiais semicondutores são matériasprimas indispensáveis na preparação de diferentes dispositivos, tais como células solares e fotoelétricas, transistores, lasers, microeletrônica, entre outros. Nas ultimas décadas, materiais semicondutores têm sido aplicados como adsorventes e catalisadores em diferentes reações químicas, principalmente, aquelas voltadas para proteção ambiental por meio das reações de fotocatálise (LENZI et al., 2011). Semicondutores são particularmente usados na fotocatálise devido à combinação favorável da estrutura eletrônica, propriedades de absorção de luz, característica de transportar carga, e tempo de vida do estado excitado. Dentre os semicondutores mais utilizados destacam-se o $\mathrm{TiO}_{2}, \mathrm{ZnO}, \mathrm{ZrO}_{2}, \mathrm{SnO}_{2}, \mathrm{CeO}_{2}$, $\mathrm{CdS}$ e $\mathrm{ZnS}$. Destes, o que tem se apresentado como um excelente catalisador na fotodegradação e na fotoredução de poluentes orgânicos e inorgânicos é o $\mathrm{TiO}_{2}$, sendo assim, objeto de vários estudos (LENZI et al., 2011; SANTANA, BONANCEA e TAKASHIMA, 2003). O $\quad \mathrm{TiO}_{2}$ é um semicondutor do tipo n, com elevada fotoatividade, baixo custo, baixa toxidade, boa estabilidade térmica, física e química, fácil disponibilidade e estável a corrosão (SANTANA, BONANCEA e TAKASHIMA, 2003). Entretanto, existem ainda problemas básicos a serem resolvidos para melhorar a atividade fotocatalítica do $\mathrm{TiO}_{2}$. Como o $\mathrm{TiO}_{2}$ comercial tem um alto bandgap (Egap $>3,2 \mathrm{eV})$, ele é excitado somente por luz UV $(\lambda<388 \mathrm{~nm})$ para injetar elétrons dentro da banda de 
condução e deixar lacunas na banda de valência. Deste modo, isto praticamente limita o uso de luz solar ou visível como uma fonte de irradiação na reação fotocatalítica com $\mathrm{TiO}_{2}$, sendo aproveitado apenas 3 a $5 \%$ do espectro solar (TOBALDI et al., 2013). O $\mathrm{ZnO}$, por sua vez, também é um semicondutor do tipo n, que tem sido extensivamente empregado na degradação fotocatalítica de águas contaminadas com diferentes poluentes (MOHAMED e SALAM, 2014), apresentando como vantagem o fato de absorver mais o espectro solar que o $\mathrm{TiO}_{2}$, o que faz com que seja considerado um fotocatalisador ideal para utilização de energia solar (SAKTHIVEL, NEPPOLIAN e SHANKAR, 2003; CHAKRABARTI e DUTTA, 2004). Várias estratégias têm sido adotadas com o propósito de aumentar a eficiência destes materiais no tratamento de efluentes industriais, dentre as quais se encontra a dopagem, na qual é possível modificar a superfície do semicondutor pela adição de metais de transição, que atuam ampliando o tempo de vida dos elétrons e das lacunas sobre a superfície dos mesmos, além de diminuírem o bandgap aumentando o espectro de absorção da luz (MOHAMED e SALAM, 2014; LENZI et al., 2011). Desta forma, este trabalho tem por objetivo a síntese $\mathrm{e}$ caracterização de materiais a base de titânia e óxido de zinco, dopados com diferentes cargas metálicas de ferro visando produzir materiais mais eficientes quando aplicados nas reações fotocalíticas .

\section{PROCEDIMENTO EXPERIMENTAL}

\subsection{Síntese dos Materiais}

Os materiais foram sintetizados pelo método da impregnação úmida com excesso de solvente. Basicamente, a metodologia utilizada consistiu em misturar o $\mathrm{TiO}_{2}$ (óxido de titanium IV da Sigma-Aldrich com 99,9\% de grau de pureza) com água desionizada, e na mistura resultante, sob baixa agitação, adicionar o nitrato de ferro (III) nonaidratado (Sigma-Aldrich, $99,9 \%$ de pureza), previamente dissolvido em água desionizada, na quantidade necessária para preparar o material na composição desejada $(5,8,10 \mathrm{e}$ $15 \%$, em massa de ferro). Em seguida, a solução foi mantida sob agitação por 12 horas, tempo necessário para ocorrer a impregnação do $\mathrm{TiO}_{2}$ com o ferro. $\mathrm{O}$ mesmo procedimento foi repetido para o $\mathrm{ZnO}$ (da Dinâmica, 99,9\% de pureza). O excesso de solvente foi eliminado por evaporação a vácuo, em evaporador rotatório, com ligeiro aquecimento, precedendo-se secagem em estufa a $100^{\circ} \mathrm{C}$ por 12 horas. Após, o material obtido foi submetido à calcinação em mufla a $400^{\circ} \mathrm{C}$ por 4 horas.

\subsection{Caracterização dos Materiais}

2.2.1 Medidas de Adsorção-Dessorção de $\mathrm{N}_{2}$

A área superficial específica $(\mathrm{Sg})$, o raio médio (rp) e o volume específico (V) de poros foram determinados no equipamento Quanta Chrome modelo Nova 1200 utilizando adsorção de $\mathrm{N}_{2}$ a $77 \mathrm{~K}$. Antes das análises propriamente ditas, as amostras não calcinadas e calcinadas foram submetidas a um tratamento térmico a $373 \mathrm{~K}$ e $573 \mathrm{~K}$, respectivamente, sob vácuo por 8 horas para as não calcinadas e 6 horas para as calcinadas, com o propósito de eliminar água e materiais adsorvidos nos poros das amostras durante a manipulação das mesmas.

\subsubsection{Análise Termogravimétrica (ATG) e Calorimetria Exploratória Diferencial (DSC)}

Para determinar a melhor temperatura de calcinação, realizou-se ATG dos óxidos após a etapa de secagem, em equipamento Analisador Termogravimétrico Shimadzu modelo TGA-50M e Microbalança Analítica Metter Toledo modelo MX5. Foi utilizada cerca de $1 \mathrm{~g}$ de amostra, a qual foi colocada em cadinho de alumínio. As condições de análises foram: vazão $50 \mathrm{~mL} / \mathrm{min}$ de $\mathrm{N}_{2}$, desde a temperatura ambiente até $1273 \mathrm{~K}$ e 
velocidade de aquecimento de $10^{\circ} \mathrm{C} / \mathrm{min}$. Com a finalidade de identificar a energia envolvida com o aumento da temperatura, realizou-se DSC com o mesmo equipamento e quantidade de amostra utilizados na análise ATG. Neste caso, as condições de análises foram: vazão $50 \mathrm{~mL} / \mathrm{min}$ de $\mathrm{N}_{2}$, desde a temperatura ambiente até $773 \mathrm{~K}$ e velocidade de aquecimento de $10^{\circ} \mathrm{C} / \mathrm{min}$.

\subsubsection{Difratometria de Raios X (DRX)}

Os difratogramas foram obtidos em um Difratômetro de raios $\mathrm{X}$, D8 Advance da Bruker, utilizando radiação $\mathrm{CuK} \alpha,(\mathrm{V}=40$ $\mathrm{KV}$, I= $35 \mathrm{~mA}$ ). Os parâmetros utilizados foram: ângulo (20) entre 29 e $70^{\circ}$; passo de $0,01^{\circ}$; velocidade de $0,28 \% \mathrm{~min}$. Os dados foram analisados com o programa $\mathrm{X}$ 'Pert HighScore.

2.2.4 Microscopia Eletrônica de Varredura (MEV) e Espectroscopia de Energia Dispersiva (EDX)

As análises de MEV e EDX foram realizadas para determinar a morfologia e a composição qualitativa dos materiais sintetizados. Para recobrimento das amostras usou-se Equipamento de recobrimento metálico Sputter Coater Emitech, modelo K450, e a espessura de camada de ouro foi estimada em $200 \mathrm{~A}^{\circ}$. Para as micrografias utilizou-se microscópio eletrônico de varredura com detector de energia dispersiva de raios X Leo Electron Microscopy, modelo MEV Leo 440i e modelo EDS 6070. Para os espectros de raios $X$ a tensão de aceleração foi de $20 \mathrm{kV}$ e corrente de feixe igual a $700 \mathrm{pA}$.

\subsubsection{Espectroscopia Fotoacústica}

A espectroscopia fotoacústica foi utilizada para determinar a energia mínima de excitação dos elétrons da banda de condução para a banda de valência, que corresponde à energia de bandgap. As condições de análise foram: $0,2 \mathrm{~g}$ de amostra, frequência de $23 \mathrm{~Hz}$, tempo de amostragem de $300 \mathrm{~ms}$ com
3 médias e tempo de espera de 1s por medida, fenda de 3,16 , filtro $\mathrm{BP} / \mathrm{F} / 2 \mathrm{~F}$ e ganho de 12 .

\subsubsection{Ponto de Carga Zero (PCZ)}

A determinação do $\mathrm{PCZ}$ foi realizada no equipamento Beckman Coulter Delsa (TM) Nano Zeta Potential and Submicron Particle Size Analyzer utilizando o software Particle Analyzer Delsa ${ }^{\mathrm{TM}}$ Nano UI versão 3.73. Antes da análise propriamente dita, uma massa de $0,06 \mathrm{~g}$ de material foi adicionada a $15 \mathrm{~mL}$ de solução nitrato de potássio $0,001 \mathrm{mols} / \mathrm{L}$. O $\mathrm{pH}$ inicial foi ajustado para 2,3,4,5,6,7,8,9,10,11 pela adição de gotas de $\mathrm{HCl} 0,1 \mathrm{mols} / \mathrm{L}$ e $\mathrm{NaOH} 0,1 \mathrm{mols} / \mathrm{L}$. Foram traçadas curvas de variação do $\mathrm{pH}$ em função da dispersão de luz eletroforética (DLE) em $\mathrm{mV}$ (milivolts), para a obtenção do valor de PCZ, que correspondeu ao valor no eixo das abscisas onde a variação do $\mathrm{pH}$ foi zero.

\section{RESULTADOS E DISCUSSÃO}

\subsection{Medidas de Adsorção-Dessorção de $\mathbf{N}_{2}$}

Os resultados obtidos para área superficial específica $(\mathrm{Sg}$ ), raio médio (rp) e volume específico (V) de poros para as amostras dopadas com ferro, não calcinadas e calcinadas (designadas pelo índice c) estão apresentados na Tabela 1. Para as amostras contendo $5 \%$ e $15 \%$ de $\mathrm{Fe}$ em $\mathrm{TiO}_{2}$, a calcinação diminuiu a área superficial, raio médio e volume de poros e aumentou tais parâmetros para àquelas com $8 \%$ e $10 \%$ de $\mathrm{Fe}$ em $\mathrm{TiO}_{2}$. Para as amostras de $\mathrm{Fe} / \mathrm{ZnO}$, o tratamento térmico atuou reduzindo a área, raio médio e volume de poros, nas amostras com $5 \%$ e $8 \%$ de $\mathrm{Fe}$, aumentando os valores destas propriedades naquelas dopadas com $10 \%$ de Fe e mantendo constante para amostra contendo $15 \%$ de Fe. Segundo Da Silva e Lasarin (2013), a redução pode ser associada com o fato de o tratamento térmico ter promovido uma sinterização dos microporos, pode-se ainda relacionar tal fato à migração de partículas ou cristais menores para 
partículas maiores ou a maior interação do metal com o suporte (SCHMAL, 2011).

Tabela 1 - Área Superficial Específica ( $\mathrm{Sg})$, Raio Médio (rp) e Volume Específico (V) de Poros.

\begin{tabular}{cccc}
\hline Amostra & $\begin{array}{c}S g \\
m^{2} / g\end{array}$ & $\begin{array}{c}R p \\
\AA\end{array}$ & $\begin{array}{c}V \\
\left(\mathrm{~cm}^{3} / g\right)\end{array}$ \\
\hline $\mathrm{TiO}_{2} \mathrm{Fe} 5 \mathrm{c}$ & 7 & 13 & 0,0003 \\
$\mathrm{TiO}_{2} \mathrm{Fe} 8 \mathrm{c}$ & 14 & 20 & 0,0092 \\
$\mathrm{TiO}_{2} \mathrm{Fe} 10 \mathrm{c}$ & 18 & 25 & 0,0166 \\
$\mathrm{TiO}_{2} \mathrm{Fe} 15 \mathrm{c}$ & 15 & 20 & 0,0106 \\
$\mathrm{TiO}_{2} \mathrm{Fe} 5$ & 8 & 20 & 0,0054 \\
$\mathrm{TiO}_{2} \mathrm{Fe} 8$ & 11 & 17 & 0,0048 \\
$\mathrm{TiO}_{2} \mathrm{Fe} 10$ & 4 & 19 & 0,0019 \\
$\mathrm{TiO}_{2} \mathrm{Fe} 15$ & 19 & 20 & 0,0012 \\
$\mathrm{ZnOFe5c}$ & 4 & 29 & 0,0038 \\
$\mathrm{ZnOFe} 8 \mathrm{c}$ & 6 & 18 & 0,0032 \\
$\mathrm{ZnOFe} 10 \mathrm{c}$ & 6 & 23 & 0,0048 \\
$\mathrm{ZnOFe} 15 \mathrm{c}$ & 8 & 26 & 0,0095 \\
$\mathrm{ZnOFe} 5$ & 12 & 22 & 0,0097 \\
$\mathrm{ZnOFe} 8$ & 17 & 23 & 0,0150 \\
$\mathrm{ZnOFe} 10$ & 12 & 23 & 0,0105 \\
$\mathrm{ZnOFe} 15$ & 8 & 27 & 0,0080 \\
\hline
\end{tabular}

Contudo, como não se observa um padrão de variação em função do tratamento térmico e ainda a pouca influência da calcinação nos parâmetros texturais, principalmente para os materiais compostos de ferro e titânia, com exceção para a amostra $\mathrm{TiO}_{2} \mathrm{Fe} 10$, pode ser que a variação obtida esteja dentro do erro experimental imposto em tais análises. Analisando as amostras de $\mathrm{TiO}_{2}$ dopadas com ferro, calcinadas, observase um acréscimo na área, raio médio e no volume de poros dos materiais à medida que a porcentagem de ferro aumenta até a razão de $10 \%$, o que se justifica pelo fato que a inserção das partículas de $\mathrm{Fe}$ na matriz do $\mathrm{TiO}_{2}$ evita a aglomeração do mesmo (MOHAMED e SALAM, 2014). Comportamento contrário é observado para o material contendo $15 \%$ de ferro, para o qual ocorre diminuição destes parâmetros. A razão para isso pode ser a elevada \% de ferro, que forma uma camada mais espessa bloqueando os poros do $\mathrm{TiO}_{2}$ (ZHANG, ZHOU e LEI, 2005). Para as amostras de $\mathrm{Fe} / \mathrm{ZnO}$, calcinadas, ocorre um aumento da área à medida que a $\%$ de ferro aumenta. A adição de ferro, neste caso, deve influenciar na formação de defeitos estruturais que se dissemina pelo suporte elevando a área e a porosidade (SRIVASTAVA e SRIVASTAVA, 2013; RAUF, MEETAM e HISAINDEE, 2011; SCHMAL, 2011). Os materiais a base de $\mathrm{TiO}_{2}$ dopados com diferentes cargas de ferro apresentaram maior área superficial do que os materiais a base de zinco, também dopados com diferentes porcentagens de ferro.

\subsection{Análise Termogravimétrica (ATG) e Calorimetria Exploratória Diferencial (DSC)}

A Figura 1 apresenta os perfis ATG/DSC obtidos para as amostras não calcinadas. A análise dos perfis ATG para as amostras de $\mathrm{Fe} / \mathrm{TiO}_{2}$ mostra ligeira perda e subseqüente ganho de massa, o que pode estar relacionado à desidratação e à oxidação das mesmas, ou ainda devido entradas/saídas de alguns gases adsorvidos na superfície dos pós, decorrente da reorganização estrutural dos cristais, constante, com o aumento da temperatura (SCHMAL, 2011; ALMEIDA, 2012). Os picos endotérmicos presentes nos perfis DSC para estas mesmas amostras justifica os efeitos do calor associados às reações de desidratação, enquanto os picos exotérmicos justificam as reações de oxidação (IONASHIRO, 2004). Para as amostras a base de $\mathrm{ZnO}$ dopadas com $\mathrm{Fe}$, os perfis ATG mostram que a $\%$ de perda de massa foi maior do que nas amostras a base de $\mathrm{TiO}_{2}$. A amostra contendo $15 \% \mathrm{Fe} / \mathrm{ZnO}$ foi a que apresentou a maior perda de massa, o que se justifica pela maior porcentagem de nitratos na superfície da amostra, havendo assim maior decomposição deste precursor. A perda de massa observada desde a temperatura ambiente até $400^{\circ} \mathrm{C}$ pode ser atribuída ainda perdas de $\mathrm{H}_{2} \mathrm{O}, \mathrm{N}_{2}, \mathrm{O}_{2}$. Após $400^{\circ} \mathrm{C}$, a massa mantém-se praticamente constante indicando 
estabilidade térmica a partir desta temperatura.

Figura 1 - Perfis ATG/DSC para amostras não Calcinadas
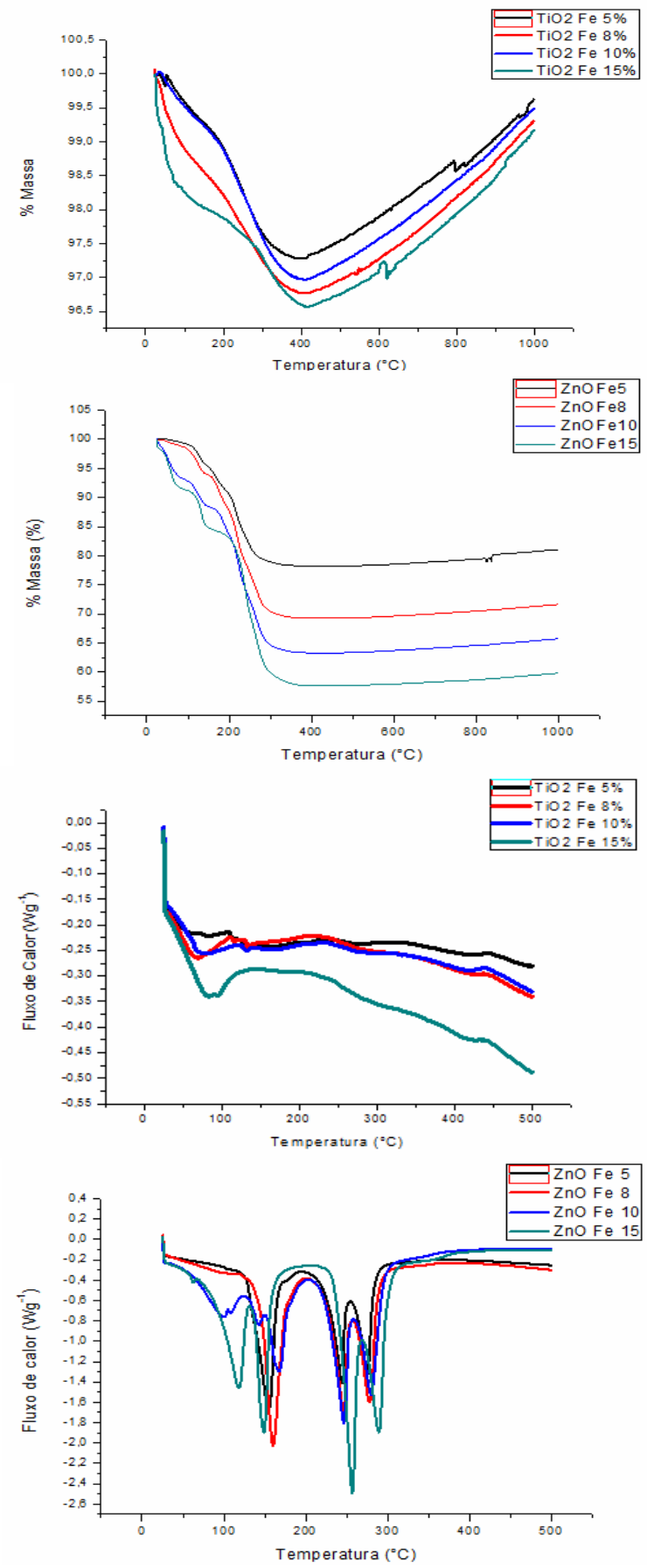

Fonte: Autores (2015).

Os perfis de DSC apresentam uma sequência de picos endotérmicos que também podem estar relacionados às perdas de massa por desidratação e decomposição, enquanto os exotérmicos explicam possíveis alterações físicas de cristalização e reações de oxidação (IONASHIRO, 2004). Desta forma, os resultados obtidos indicam que a calcinação a $400^{\circ} \mathrm{C}$ foi suficiente para decompor a água e os compostos adsorvidos na superfície da amostra durante a etapa de preparação, conduzindo à formação de óxidos.

\subsection{Difratometria de Raios X (DRX)}

Os difratogramas obtidos com DRX estão apresentados nas Figuras 2 e 3 para as amostras de $\mathrm{TiO}_{2}$ e $\mathrm{ZnO}$, dopadas com Fe, respectivamente. Os picos observados foram comparados com o banco de dados do programa X'Pert HighScore e com os padrões publicados pela JCPDS (1995). Os dados de difração obtidos para as amostras a $\mathrm{Fe} / \mathrm{TiO}_{2}$, não calcinadas e calcinadas mostram que o tratamento térmico não afetou a cristalinidade da titânia, sendo que a fase anatase (2 $\theta$ $=25,32^{\circ} ; 36,95^{\circ} ; 37,81^{\circ} ; 38,58^{\circ} ; 48,04^{\circ}$; $53,9^{\circ} ; 55,07^{\circ} ; 62,13^{\circ} ; 62,7^{\circ}$ e $68,77^{\circ}$ ), foi observada em todas as amostras, conforme ICSD 84-1285. As amostras de $\mathrm{TiO}_{2}$ dopadas com 8,10 e $15 \%$ de ferro apresentaram picos relativos ao óxido de ferro, os quais foram mais intensos nas amostras calcinadas. Não foi possível observar a presença picos referentes ao ferro para a amostra $5 \% \mathrm{Fe} / \mathrm{TiO}_{2}$. Para as amostras de Fe/ZnO, observa-se após a calcinação uma definição das regiões cristalinas de $\mathrm{ZnO}$ na forma de wurtzita $(2 \theta=$ $31,78^{\circ} ; 34,44^{\circ} ; 36,27^{\circ} ; 47,55^{\circ} ; 56,60^{\circ} ; 62,86^{\circ}$; $66,37^{\circ} ; 67,94^{\circ}$ e $69,08^{\circ}$ ), conforme JCPDS PDF \# 36-1451. A amostra 5\% Fe/ZnO, calcinada, apresentou o mesmo perfil de cristalinidade obtido para o $\mathrm{ZnO}$ puro. Chakma et al. (2013), afirmam que tal comportamento é devido à baixa concentração de ferro na amostra, e como o raio iônico do $\mathrm{Fe}^{3+}$ é próximo ao do $\mathrm{Zn}{ }^{2+}$, pode-se inferir que $\mathrm{Fe}^{3+}$ adentre a estrutura cristalina do semicondutor. 
Figura 2 - DRX para amostras de $\mathrm{TiO}_{2}$ Pura e

Dopadas com Ferro, não Calcinadas e Calcinadas
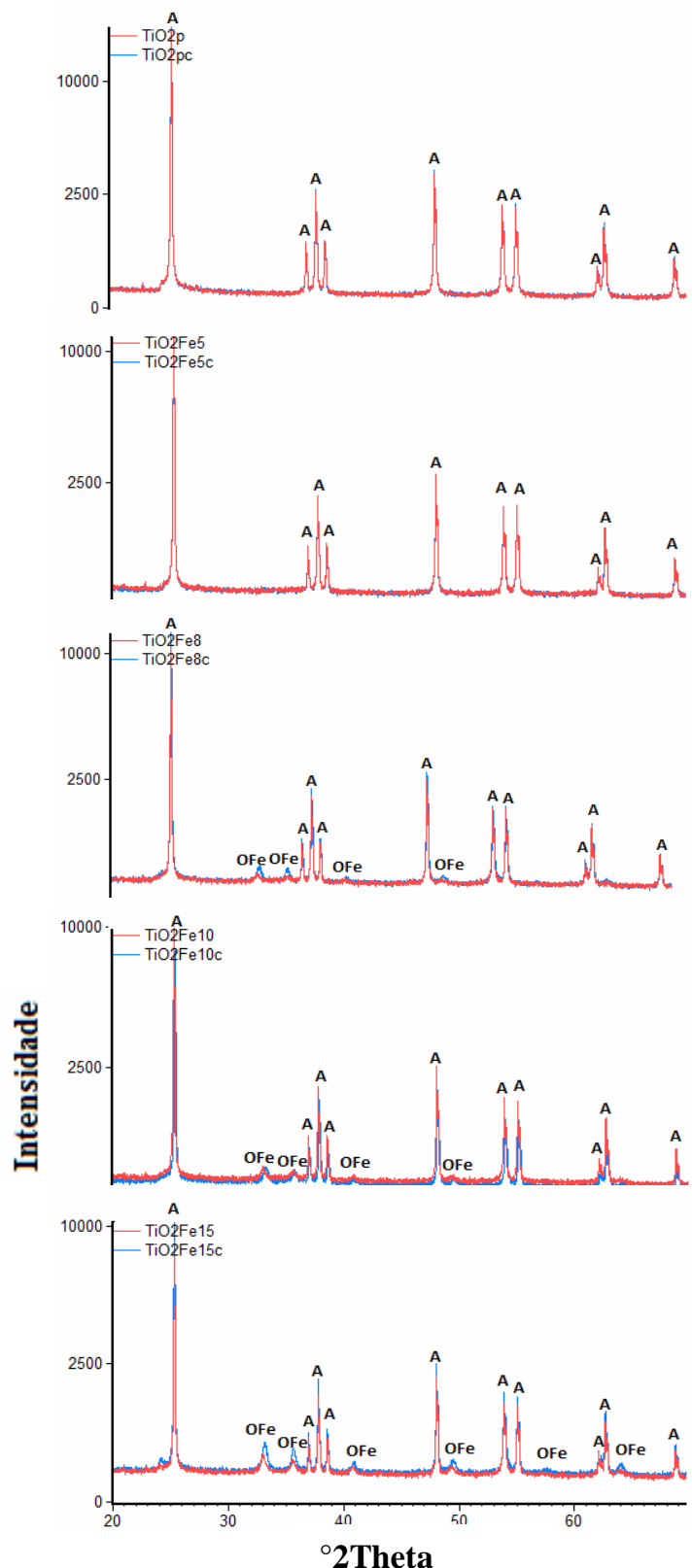

Fonte: Autores (2015)

Por sua vez, os difratogramas obtidos para as amostras contendo 8, 10 e $15 \%$ de ferro em zinco, não calcinadas, são típicos de material amorfo, o que demonstra a necessidade do tratamento térmico para ordenação dos átomos no cristal e obtenção de uma fase cristalina, tal fato fundamenta os dados de DSC no que concerne às reações exotérmicas para a reestruturação dos cristais, e justifica a alta área superficial encontrada para estes óxidos (FERRARI-LIMA, 2013).

Figura 3 - DRX para amostras de $\mathrm{ZnO}$ Puro e Dopada com Ferro, não Calcinadas e Calcinadas
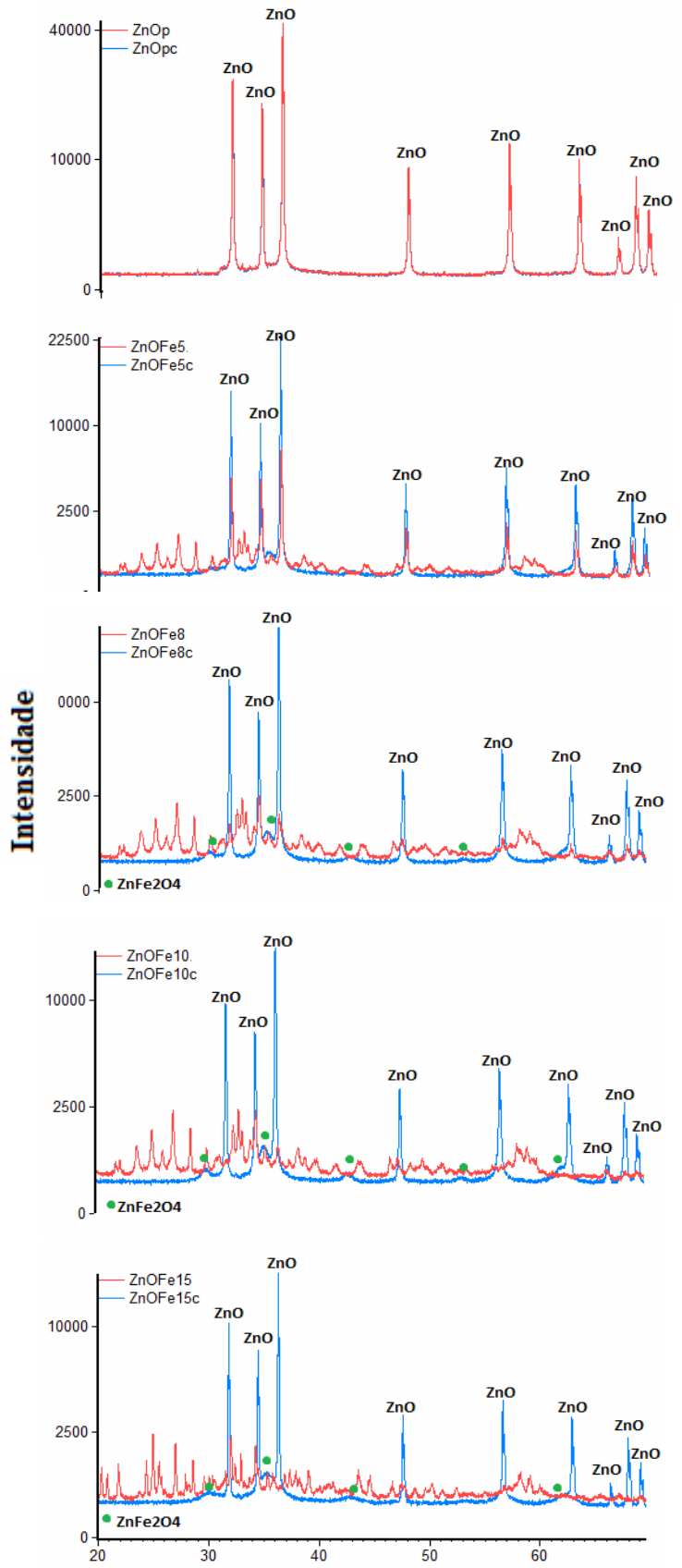

${ }^{\circ}$ 2Theta

Fonte: Autores (2015) 
As amostras dopadas com $8 \%$ de ferro $\left(2 \theta=29,98^{\circ} ; 35,13^{\circ} ; 36,25^{\circ}\right.$ e $\left.53,17^{\circ}\right), 10 \%$ de ferro $\left(2 \theta=29,89^{\circ} ; 35,15^{\circ} ; 42,71^{\circ}, 53,04^{\circ} \mathrm{e}\right.$ $\left.62,07^{\circ}\right)$, e $15 \%$ de ferro $\left(2 \theta=29,95^{\circ} ; 35,12^{\circ}\right.$; 42,74 e $61,86^{\circ}$ ), calcinadas, apresentaram picos referentes ao $\mathrm{ZnFe}_{2} \mathrm{O}_{4}$, conforme ICSD 74-2397, ICDS 82-1042 e ICDS 06-6128 respectivamente. A forma wurtzita observada para o $\mathrm{ZnO}$ puro não calcinado, também foi observada para o zinco e para as amostras de zinco dopadas com ferro, calcinadas.

\subsection{Microscopia Eletrônica de Varredura (MEV) e Espectroscopia de Energia Dispersiva (EDX)}

As Figuras 4, 5 e 6 mostram as micrografias, obtidas por $\mathrm{MEV}$, para os materiais, a base de $\mathrm{TiO}_{2}$, dopados com 5, 10 e $15 \%$, em massa, de ferro, com ampliações de 100,500 e 2000 vezes, respectivamente.

Figura 4 - Micrografia da amostra $5 \% \mathrm{Fe} / \mathrm{TiO}_{2}$

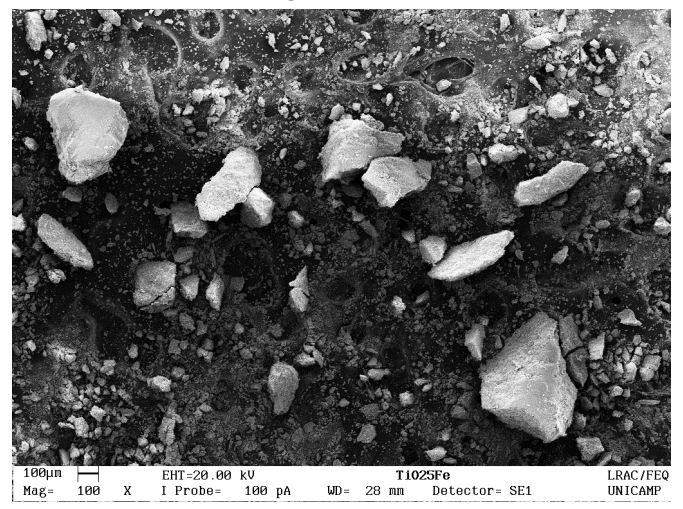

Figura 5 - Micrografia da amostra $10 \% \mathrm{Fe} / \mathrm{TiO}_{2}$

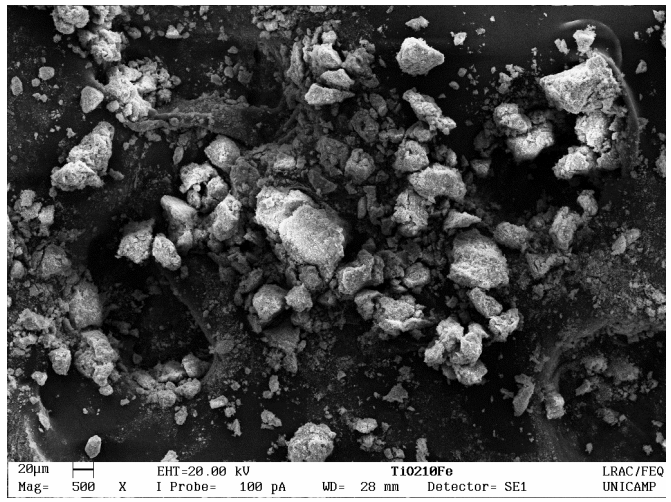

Figura 6 - Micrografia da amostra $15 \% \mathrm{Fe} / \mathrm{TiO}_{2}$

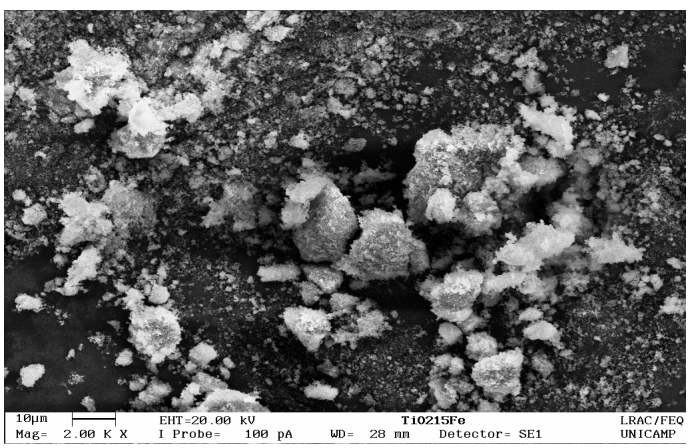

Observa-se pelas micrografias que os materiais a base de titânia, dopados com ferro, não calcinados, apresentam uma estrutura superficial pouco porosa e irregular formada por partículas, ou aglomerados não uniformes. As Figuras 7, 8, 9, 10, por sua vez, apresentam as micrografias obtidas para os materiais, a base de zinco, dopados com 5, 8, 10 e $15 \%$, em massa de ferro, com ampliações de 500, 1000, 2000 e 5000 vezes, respectivamente.

Figura 7 - Micrografia da amostra $5 \% \mathrm{Fe} / \mathrm{ZnO}$

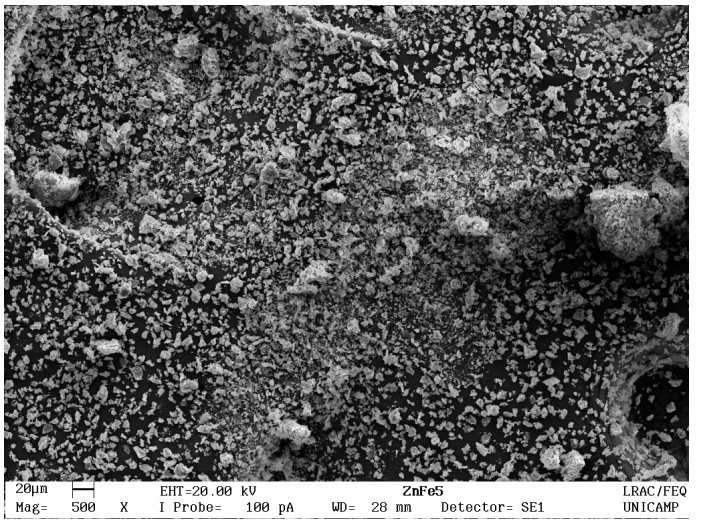

De acordo com resultados obtidos, observa-se pelas micrografias que os materiais a base de zinco, dopados com ferro, não calcinados, apresentam uma estrutura superficial mais porosa do que a observada para os materiais a base de $\mathrm{TiO}_{2}$ de formato lamelar/escamas e uniformes (Figura 10).

As Figuras 11 e 12 apresentam, respectivamente, espectros $\mathrm{EDX}$ típicos obtidos para as amostras de $8 \% \mathrm{Fe} / \mathrm{TiO}_{2}$ e $8 \% \mathrm{FeZnO}$, não calcinados. A Tabela 2, por 
sua vez, apresenta os resultados identificando para cada amostra a porcentagem mássica e atômica de cada elemento. Resultados similares foram obtidos para as amostras contendo cargas metálicas de 5, 10 e $15 \%$, em massa de ferro.

Figura 8 - Micrografia da amostra $8 \% \mathrm{Fe} / \mathrm{ZnO}$

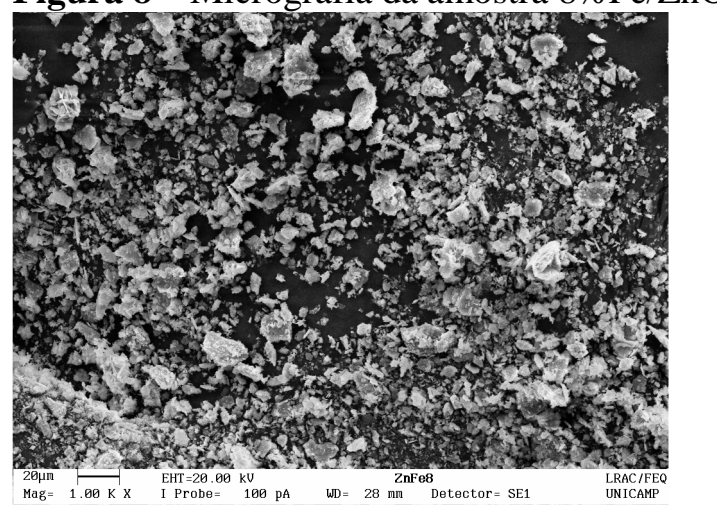

Figura 9 - Micrografia da amostra $10 \% \mathrm{Fe} / \mathrm{ZnO}$

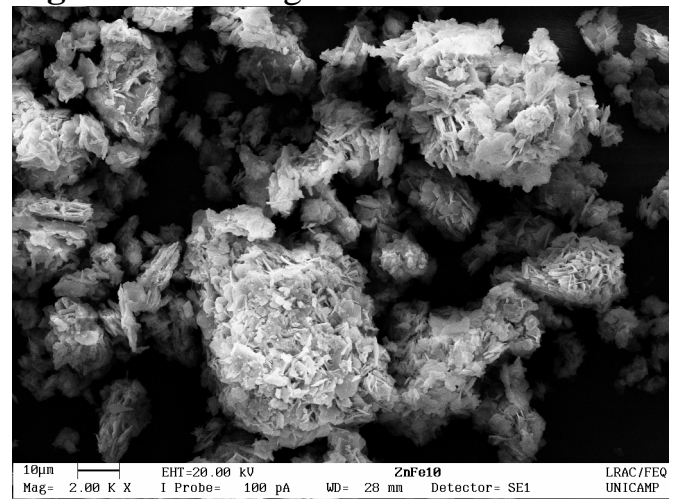

Figura 10 - Micrografia da amostra $15 \% \mathrm{Fe} / \mathrm{ZnO}$

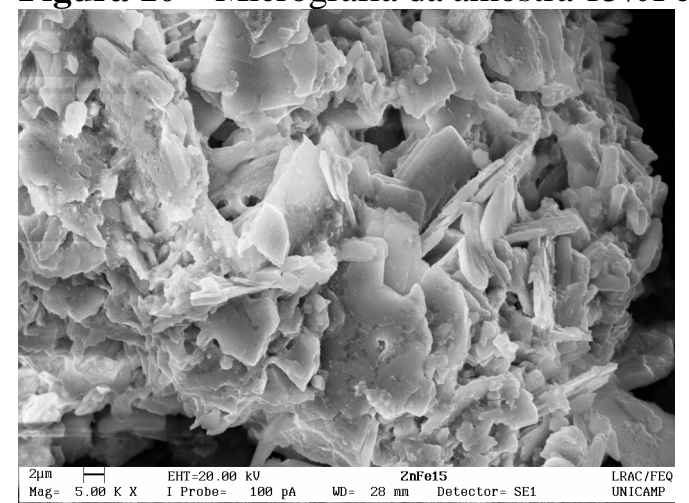

De acordo com os resultados obtidos (Figuras 11 e 12, Tabela 2) foi identificada, nas amostras, a presença de $\mathrm{O}, \mathrm{Fe}, \mathrm{Zn}$ e Ti.
Observa-se ainda que a inserção de ferro na matriz de zinco foi levemente maior do que na matriz de titânia (Tabela 2).

Figura 11 - EDX para 8\%Fe/ZnO, não calcinada cps

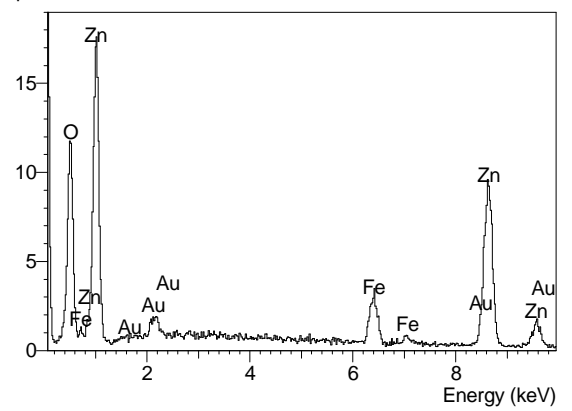

Figura 12 - EDX para $8 \% \mathrm{Fe} / \mathrm{TiO}_{2}$, não calcinada cps

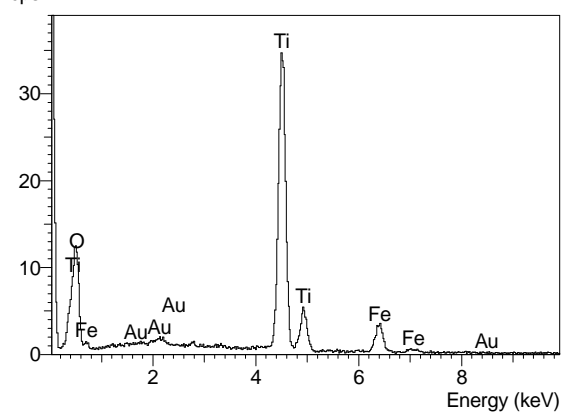

Tabela 2 - Elementos Presentes na Amostra

\begin{tabular}{cccc}
\hline Amostra & Elemento & \%Mássica & \%Atômica \\
\hline \multirow{3}{*}{$8 \% \mathrm{Fe} / \mathrm{ZnO}$} & $\mathrm{O}$ & 33,01 & 66,43 \\
& Fé & 6,69 & 3,86 \\
& $\mathrm{Zn}$ & 60,31 & 29,71 \\
\hline \multirow{3}{*}{$8 \% \mathrm{Fe} / \mathrm{TiO}_{2}$} & $\mathrm{O}$ & 60,62 & 82,48 \\
& $\mathrm{Fé}$ & 5,85 & 2,28 \\
& $\mathrm{Ti}$ & 33,52 & 15,23 \\
\hline
\end{tabular}

\subsection{Espectroscopia Fotoacústica}

Os resultados obtidos com espectroscopia fotoacústica para a titânia e zinco, dopadas com diferentes cargas metálicas de ferro, calcinadas, são mostrados na Tabela 3. A absorção de radiação é de fundamental importância para descrever o comportamento das reações fotocatalíticas, devendo ser igual ou superior à energia de band gap, o qual para anatase é de $3,2 \mathrm{eV}$ e equivale a um comprimento de onda de 388nm, para óxido de zinco o band gap é de 
3,37 eV equivalendo a um comprimento de onda de 400nm. Os dados da Tabela 3 mostram que a dopagem dos óxidos com ferro resultou na redução do band gap dos materiais quando comparados aos óxidos puros, deslocando o espectro de absorção para a região visível, permitindo, assim, o uso destes materiais na presença de fontes de radiação de menor energia (FERRARI-LIMA, 2013).

Tabela 3 - Band gap para materiais dopados com diferentes porcentagens de ferro

\begin{tabular}{c|cc}
\hline Amostra & Band gap (eV) & $\begin{array}{c}\text { Comprimento } \\
\text { de onda } \lambda \\
(\text { nm })\end{array}$ \\
\hline TiO2Fe5c & 1,73 & 716,76 \\
TiO2Fe8c & 1,65 & 751,51 \\
TiO2Fe10c & 1,628 & 761,67 \\
TiO2Fe15c & 1,633 & 759,33 \\
ZnOFe5c & 1,94 & 639,17 \\
ZnOFe8c & 1,83 & 677,60 \\
ZnOFe10c & 1,84 & 673,91 \\
ZnOFe15c & 1,55 & 800 \\
\hline
\end{tabular}

Fonte: Autores (2015)

\subsection{Ponto de Carga Zero (PCZ)}

A Figura 13 apresenta os resultados obtidos com análise de PCZ para o $\mathrm{ZnO}$ e $\mathrm{TiO}_{2}$, calcinados, para $15 \% \mathrm{Fe} / \mathrm{ZnO}$ e $15 \% \mathrm{Fe} / \mathrm{TiO}_{2}$, não calcinados e para $15 \% \mathrm{Fe} / \mathrm{TiO}_{2}$, calcinado. Nota-se que a adição de ferro na matriz dos óxidos e o tratamento térmico afetam consideravelmente a distribuição de cargas na superfície dos semicondutores. De acordo com os resultados obtidos os valores de PCZ foram de 6; 3; 4,9; 3 ; e 9,8 , para as amostras $15 \% \mathrm{Fe} / \mathrm{TiO}_{2}$, não calcinada, $\quad \mathrm{TiO}_{2}, \quad$ calcinada, $15 \% \mathrm{Fe} / \mathrm{TiO}_{2}$, calcinada, $15 \% \mathrm{Fe} / \mathrm{ZnO}$, não calcinada e $\mathrm{ZnO}$, calcinado, respectivamente. Para amostras contendo $15 \%$ de ferro em titânia, a calcinação provocou uma redução no $\mathrm{PCZ}$, de 6,0 para 4,9 enquanto que a adição de ferro na matriz da titânia provocou um aumento no PCZ de 3 para 4,9 .
Figura 13 - PCZ para semicondutores puros e dopados, com e sem tratamento térmico

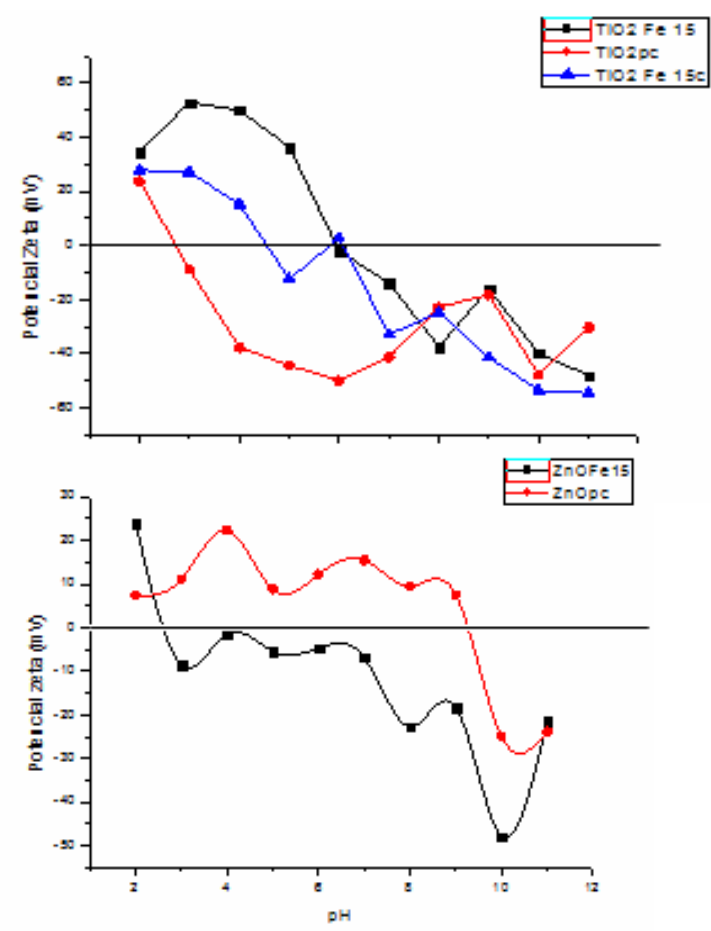

Fonte: Autores (2015)

\section{CONCLUSÕES}

A adição de ferro na matriz dos óxidos semicondutores e o tratamento térmico de calcinação modificaram as características morfológicas, texturais e físico-químicas da titânia e do óxido de zinco.

\section{REFERÊNCIAS}

ALMEIDA, W. M. Síntese e Avaliação da Atividade Fotocatalítica do $\mathrm{Ag}_{2} \mathrm{O} / \mathrm{TiO}_{2}$ na degradação de corante. 2012. Dissertação (Mestrado em Ciência e Tecnologia Ambiental) - Universidade Estadual da Paraíba, Campina Grande, 2012.

CHAKMA, S; BHASARKAR, J. B; MOHOLKAR, V. S. Preparation, characterization and application of sonochemically doped $\mathrm{Fe}^{+3}$ into $\mathrm{ZnO}$ nanoparticles. International Journal of 
Research in Engineering and Technology, p.177-183, 2013.

CHAKRABARTI, S; DUTTA, B. K. Photocatalytic degradation of model textile dyes in wastewater using $\mathrm{ZnO}$ as semiconductor catalyst. Journal of Harzadous Materials B, v.112, p.269-278, 2004.

DA SILVA, W. L; LASARIN, M. A. Síntese, caracterização e atividade fotocatalítica de catalisadores nanoestruturados de $\mathrm{TiO}_{2}$ dopados com metais. Química Nova, v.36, p.382-386, 2013.

FERRARI-LIMA, A. M. Fotodegradação de Efluente de Terminal de Combustível com Catalisadores Dopados. 2013. 170p. Tese (Doutorado em Engenharia Química) Universidade Estadual de Maringá, Maringá, 2013.

IONASHIRO, M. Giolito: Fundamentos da Termogravimetria, Análise Térmica Diferencial, Calorimetria Exploratória Diferencial. Araraquara: Giz editorial, 2004.

LENZI, G. G; FÁVERO, C. V. B; COLPINI, L. M. S; BERNABE, H; BAESSO, M. L; SPECCHIA, S; SANTOS, O. A. A. Photocatalytic reduction of $\mathrm{Hg}(\mathrm{II})$ on $\mathrm{TiO}_{2}$ and $\mathrm{Ag} / \mathrm{TiO}_{2}$ prepared by the sol-gel and impregnation methods. Desalination, v.270, p.241-247, 2011.

MOHAMED, R. M.; SALAM, M. A. Photocatalytic reduction of aqueous mercury (II) using multi-walled carbon nanotubes.PdZno nanocomposite. Material Research Bulletin, v.50, p.85-90, 2014.

RAUF, M. A; MEETANI, M. A; HISAINDEE, $S$. An overview of the photocatalytic degradation of azo dyes in presence of $\mathrm{TiO}_{2}$ doped with selective transition metals. Desalination, v.276, p.1327, 2011.

SAKTHIVEL, $\mathrm{S} ; \quad$ NEPPOLIAN, $\mathrm{B}$; SHANKAR, M. V. Solar photocatalytic degradation of azo dye: comparison of photocatalytic efficiency of $\mathrm{ZnO}$ and $\mathrm{TiO}_{2}$. Solar Energy Materials \& Solar Cells, v.77, p.65-82, 2003.

SANTANA, H., BONANCEA, C. E., AKASHIMA, K. Fotocatalise eletroquímica de atrazina sobre dióxido de titânio: efeito de diferentes parâmetros experimentais. Química Nova, v.26, p.807-811, 2003.

SCHMAL, M. Catálise Heterogênea. Rio de Janeiro, Synergia editor, 2011.

SRIVASTAVA， P; SRIVASTAVA， V. C; Photocatalytic oxidation of dye bearing wastewaterby iron doped zinc oxide. Industrial \& Engineering Chemistry Research, v. 52, p.17790-17799, 2013.

TOBALDI, D. M; SKAPIN, A. S; PULLAR, R. C; SEABRA, M. P; LABRINCHA, J. A. Titanium dioxide modified with transition metals and rare earth elements: Phase composition, optical properties, and photocatalytic activity. Ceramics International, v.39, p. 2619-2629, 2013.

ZHANG, X; ZHOU, M; LEI, L. Preparation of anatase $\mathrm{TiO}_{2}$ supported on alumina by diferente metal organic chemical deposition methods. Applied Catalysis A: General, v.282, p.285-293, 2005.

\section{AGRADECIMENTOS}

Os autores agradecem ao $\mathrm{CNPq}$ e a CAPES, pelo suporte financeiro. 